\title{
Tronchuda cabbage (Brassica oleracea L. var. costata DC) seeds: Phytochemical characterization and antioxidant potential
}

\author{
Federico Ferreres ${ }^{\text {a }}$, Carla Sousa ${ }^{\text {b }}$, Patrícia Valentão ${ }^{b}$, Rosa M. Seabra ${ }^{b}$, \\ José A. Pereira $^{\text {c }}$, Paula B. Andrade ${ }^{\mathrm{b}, *}$ \\ ${ }^{a}$ Research Group on Quality, Safety and Bioactivity of Plant Foods, Department of Food Science and Technology, CEBAS (CSIC), P.O. Box 164, \\ 30100 Campus University, Espinardo (Murcia), Spain

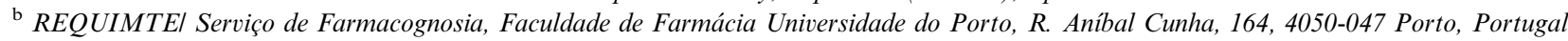

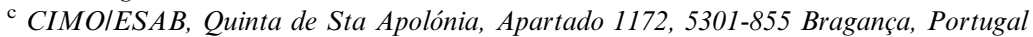

Received 2 November 2005; received in revised form 13 December 2005; accepted 13 February 2006

\begin{abstract}
Tronchuda cabbage (Brassica oleracea L. var. costata DC) seeds were studied for their chemical composition and antioxidant capacity. Thirteen phenolic compounds were characterized and quantified by reversed-phase HPLC-DAD-MS/MS-ESI and HPLC-DAD, respectively: two sinapoylgentiobiose isomers, three sinapoylglucose isomers, kaempferol-3-(sinapoyl)sophorotrioside-7-glucoside, sinapoylcholine, kaempferol-3,7-diglucoside- $4^{\prime}$-(sinapoyl)glucoside, three disinapoylgentiobiose isomers, 1,2,2'-trisinapoylgentiobiose and 1,2-disinapoylglucose. Seven organic acids (aconitic, citric, ascorbic, malic, quinic, shikimic and fumaric acids) were also identified and quantified by HPLC-UV. The aqueous extract of tronchuda cabbage seeds was investigated for its capacity to act as a scavenger of DPPH' radical and reactive oxygen species (superoxide radical, hydroxyl radical and hypochlorous acid), exhibiting antioxidant capacity in a concentration-dependent manner against all radicals. These results may be attributed to the high content of hydroxycinnamic derivatives and ascorbic acid.
\end{abstract}

(C) 2006 Elsevier Ltd. All rights reserved.

Keywords: Tronchuda cabbage seeds; Brassica oleracea L. var. costata DC; Phenolic compounds; Organic acids; Antioxidant capacity

\section{Introduction}

Brassicaceous plants represent one of the major vegetable crops grown, worldwide, constituting an important part of a well balanced diet. Brassica oleracea is a native of the Mediterranean region and southwestern Europe, extending northward to southern England (Vaughan and Geissler, 1997a). It is easy to grow in cold weather, requires moist soil and can tolerate maritime exposure. Horticultural selection within the species has led to the development of a number of cultivars and, although essentially temperate, $B$. oleracea forms are today grown for food everywhere that plants can grow (Vaughan and Geissler, 1997a). Tron-

\footnotetext{
${ }^{*}$ Corresponding author. Tel.: +351 222078935; fax: +351 222003977.

E-mail address: pandrade@ff.up.pt (P.B. Andrade).
}

chuda cabbage (B. oleracea $\mathrm{L}$. var. costata DC) is especially popular in Portugal, having a determinant role in the Portuguese diet and agricultural systems.

An increasing amount of evidence shows the need for a constant supply of phytochemical-containing plants to achieve optimal health benefits. This is ascribed to the fact that different plants have distinct compound contents, with several structures, thus offering different protective mechanisms at different levels (Chu, Sun, Wu, and Liu, 2002; Ninfali and Bacchiocca, 2003). Among phtyochemicals, phenolic compounds and organic acids may exert a protective role against various diseases, due to their antioxidant potential (Silva et al., 2004). In addition, these compounds are known to play an important role in maintaining fruit and vegetable quality, contributing to their organoleptic characteristics (Vaughan and Geissler, 1997 b), and have also been used for the quality control of several matrices 
(Valentão et al., 2005; Valentão, Andrade, Areias, Ferreres, and Seabra, 1999).

The phenolic composition of tronchuda cabbage leaves has already been reported: the external leaves were characterized by the presence of complex flavonol glycosides (Ferreres et al., 2005), while the internal ones exhibited both flavonol glycosides and hydroxycinnamic acid derivatives (Ferreres et al., 2006). The organic acids profile and the antioxidant capacity of external and internal leaves were also previously described (Ferreres et al., 2006; Vrchovska et al., 2006), with the external ones exhibiting higher antioxidant potential. However, nothing has been reported about tronchuda cabbage seeds. In fact, several studies with other Brassica species have reported the existence of phenolics in the seeds, namely phenolic acids and their derivatives (Baumert et al., 2005; Bouchereau, Hamelin, Lamour, Renard, and Larher, 1991; Li and El Rassi, 2002; Naczk, Amarowicz, Sullivan, and Shahidi, 1998), flavonoid glycosides (Baumert et al., 2005) and tannins (Naczk et al., 1998). These compounds have been considered as UV screens in young seedlings (Gitz, Liu, and McClure, 1998) and have been associated with seedling vigour, height and weight (Randhir and Shetty, 2003; Randhir and Shetty, 2005). Regarding B. oleracea seeds, previous studies with different varieties, other than costata, concerned its germination sensitivity to hypoxia (Finch-Savage, Côme, Lynn, and Corbineau, 2005), the effect of its film-coating to control insect pests (Ester, Putter, and Bilsen, 2003), the determination of glucosinolates (Kaoulla, MacLeod, and Gil, 1980; MacLeod, MacLeod, and Reader, 1989; Rangkadilok et al., 2002a, 2002 b), fatty acids (Ayaz et al., 2006) and sterols (Matsumoto, Shimizu, Asano, and Itoh, 1983).

Thus, the objectives of this study were to define the phenolic and organic acid compositions of tronchuda cabbage seeds and to evaluate their antioxidant potential. Phenolic profile was established by reversed-phase HPLC-DADMS/MS-ESI and HPLC-DAD analysis, while organic acids were determined by HPLC/UV. The antioxidant capacity was assessed by DPPH' radical and reactive oxygen species (superoxide radical, hydroxyl radical and hypochlorous acid)-scavenging assays.

\section{Materials and methods}

\subsection{Standards and reagents}

Malic, quinic, shikimic and fumaric acids were purchased from Sigma (St. Louis, MO, USA). Aconitic, citric, ascorbic and sinapic acids and kaempferol-3-O-rutinoside were from Extrasynthése (Genay, France). Methanol, formic and acetic acids were obtained from Merck (Darmstadt, Germany) and sulphuric acid from Pronalab (Lisboa, Portugal). The water was treated in a Milli-Q water purification system (Millipore, Bedford, MA, USA). DPPH, xanthine, xanthine oxidase (XO) grade I from buttermilk (EC 1.1.3.22), $\beta$-nicotinamide adenine dinucleotide (NADH), phenazine methosulfate (PMS), nitroblue tetrazolium chloride (NBT), anhydrous ferric chloride $\left(\mathrm{FeCl}_{3}\right)$, ethylenediaminetetraacetic acid disodium salt (EDTA), ascorbic acid, trichloroacetic acid, thiobarbituric acid, deoxyribose, sodium hypochlorite solution with $4 \%$ available chlorine $(\mathrm{NaOCl})$, and 5,5'-dithiobis(2-nitrobenzoic acid) (DTNB) were obtained from Sigma Chemical Co. (St. Louis, USA).

\subsection{Samples}

Tronchuda cabbages seeds were obtained from local farmers in Bragança, Northeast Portugal, in July 2005.

\subsection{Sample preparation}

An aqueous extract was used for the phytochemical characterization and in the antioxidant activity assays: $\approx 6.0 \mathrm{~g}$ of powdered tronchuda cabbage seeds were boiled for one hour in $600 \mathrm{ml}$ of water and then filtered over a Büchner funnel. The resulting extract was lyophilized in a Labconco 4.5 Freezone apparatus (Kansas City, MO, USA) and a yield of $\approx 0.9 \mathrm{~g}$ was obtained. The lyophilized extract was kept in an desiccator, in the dark.

For the characterization and quantification of the phenolic compounds by HPLC-DAD-MS/MS-ESI and HPLC-DAD, respectively, the lyophilized extract was redissolved in water $(100 \mathrm{mg} / \mathrm{ml})$, ultra-sonicated, centrifuged and filtered $(0.45 \mu \mathrm{m})$. For organic acids determination it was redissolved in $0.01 \mathrm{~N}$ sulphuric acid $(100 \mathrm{mg} / \mathrm{ml})$ prior to analysis by HPLC-UV.

\subsection{HPLC-UV analysis of organic acids}

The separation of the organic acids present in the seed lyophilized extract was carried out as previously reported, in a system consisting of an analytical HPLC unit (Gilson) with an ion exclusion column, Nucleogel ${ }^{\circledR}$ Ion 300 OA $(300 \times 7.7 \mathrm{~mm})$ in conjunction with a column heating device set at $30^{\circ} \mathrm{C}$. Briefly, elution was carried out isocratically, at a solvent flow rate of $0.2 \mathrm{ml} \mathrm{min}{ }^{-1}$, with $0.01 \mathrm{~N}$ sulphuric acid (Ferreres et al., 2006). The detection was performed with a UV detector set at $214 \mathrm{~nm}$.

Organic acids quantification was achieved by the absorbance recorded in the chromatograms relative to external standards. Malic and quinic acid were quantified together as malic acid. The average regression equations for aconitic, citric, ascorbic, malic, shikimic and fumaric acids were $y=$ $3.29 \times 10^{7} x, y=7.90 \times 10^{7} x, \quad y=1.33 \times 10^{7} x, \quad y=5.95 \times$ $10^{7} x, y=4.84 \times 10^{9} x$ and $y=1.05 \times 10^{10} x$, respectively. The detection limit values ranged from 0.01 to $1.67 \mu \mathrm{g} / \mathrm{ml}$.

\subsection{HPLC-DAD-MS/MS-ESI qualitative analysis of phenolic compounds}

Chromatographic separations were carried out on a $250 \times 4 \mathrm{~mm}, 5 \mu \mathrm{m}$ particle size, RP-18 LiChroCART (Merck, Darmstadt, Germany) column protected with a 
$4 \times 4 \mathrm{~mm}$ LiChroCART guard column. Elution was performed using acetic acid 1\% (A) and methanol (B) as solvents, starting with $20 \% \mathrm{~B}$ and using a gradient to obtain $50 \% \mathrm{~B}$ at $30 \mathrm{~min}$ and $80 \% \mathrm{~B}$ at $37 \mathrm{~min}$. In the MS/MS positive ionisation mode study, $1 \%$ formic acid was used instead of acetic acid, in order to enhance ionisation. The flow rate was $1 \mathrm{ml} \mathrm{min}^{-1}$ and the injection volumes varied between 10 and $50 \mu 1$.

The HPLC system was equipped with an Agilent 1100 Series diode array and a mass detector in series (Agilent Technologies, Waldbronn, Germany). It consisted of a G1312A binary pump, a G1313A autosampler, a G1322A degasser and a G1315B photo-diode array detector controlled by ChemStation software (Agilent, v. 08.03). Spectroscopic data from all peaks were accumulated in the range $240-400 \mathrm{~nm}$, and chromatograms were recorded at $330 \mathrm{~nm}$. The mass detector was a G2445A Ion-Trap Mass Spectrometer equipped with an electrospray ionisation (ESI) system and controlled by LCMSD software (Agilent, v. 4.1.). Nitrogen was used as nebulizing gas at a pressure of $65 \mathrm{psi}$ and the flow was adjusted to $111 \mathrm{~min}^{-1}$. The heated capillary and voltage were maintained at $350^{\circ} \mathrm{C}$ and $4 \mathrm{kV}$, respectively. The full scan mass covered the range from $\mathrm{m} / \mathrm{z} 90$ up to $\mathrm{m} / \mathrm{z} 2000$. Collisioninduced fragmentation experiments were performed in the ion trap using helium as collision gas, with voltage ramping cycles from 0.3 up to $2 \mathrm{~V}$. MS data were acquired in the negative ionisation mode and in the positive ionisation mode for the study of compound $7 . \mathrm{MS}^{n}$ data were achieved in the automatic mode on the more abundant fragment ion in $\mathrm{MS}^{n-1}$. Table 1 shows the most frequent ions which characterize the fragmentation of the compounds. Other ions were found but they have not been included due to their low significance. The classical nomenclature for glycoconjugates was adopted to designate the fragment ions. The ions ${ }^{k, l} \mathrm{X}_{j}$ represent fragments still containing the aglycone, where $j$ is the number of the interglycosidic bond broken, counted from the aglycone, and the $k$ and $l$ denote the cleavage within carbohydrate rings (Domon and Costello, 1988; Ferreres, Llorach, and GilIzquierdo, 2004; Hvattum and Ekeberg, 2003). For a better comprehension, data in Table 1 were grouped according to sinapoyl derivatives, relative to the number of acid molecules and, among these, by isomers. Data for sinapoyl derivatives from flavonoid glycosides were also included in this table.

\subsection{HPLC-DAD quantitative analysis of phenolic compounds}

Twenty microlitres of the seeds' lyophilized extract were analysed using an HPLC unit (Gilson) and a RP18 LiChroCART (Merck, Darmstadt, Germany) column $(250 \times 4 \mathrm{~mm}, 5 \mu \mathrm{m}$ particle size $)$, under the conditions described for the qualitative analysis. Detection was achieved with a Gilson diode array detector. Spectral data from all peaks were accumulated in the range of
$200-400 \mathrm{~nm}$, and chromatograms were recorded at $330 \mathrm{~nm}$. The data were processed on a Unipoint Sortware system (Gilson Medical Electronics, Villiers le Bel, France). Peak purity was checked by the software contrast facilities.

Phenolic compounds quantification was achieved by the absorbance recorded in the chromatograms relative to external standards. Since standards of the compounds identified in the seeds' lyophilized extract were not commercially available, sinapic acid derivatives were quantified as sinapic acid and the kaempferol derivatives as kaempferol-3-O-rutinoside. The average regression equations for sinapic acid and kaempferol 3-O-rutinoside were $y=$ $1.71 \times 10^{9} x$ and $y=7.42 \times 10^{8} x$, respectively. The detection limit was $5.9 \mu \mathrm{g} / \mathrm{ml}$ for sinapic acid and $4.4 \mu \mathrm{g} / \mathrm{ml}$ for kaempferol 3-O-rutinoside.

\subsection{DPPH' scavenging activity}

The antiradical activity of the extracts was determined spectrophotometrically in an ELX808 IU Ultra Microplate Reader (Bio-Tek Instruments, Inc.), by monitoring the disappearance of $\mathrm{DPPH}^{-}$at $515 \mathrm{~nm}$, according to a described procedure (Ferreres et al., 2006; Vrchovska et al., 2006). For each extract, a dilution series composed of five different concentrations was prepared in a 96 well plate. The reaction mixtures in the sample wells consisted of $25 \mu \mathrm{l}$ of aqueous extract and $200 \mu \mathrm{l}$ of $\mathrm{DPPH}^{*}$ dissolved in methanol. The plate was incubated for $30 \mathrm{~min}$ at room temperature. Three experiments were performed in triplicate.

\subsection{Evaluation of superoxide radical-scavenging activity}

\subsubsection{General}

Antiradical activity was determined spectrophotometrically in an ELX808 IU Ultra Microplate Reader (BioTek Instruments, Inc.), by monitoring the effect of the lyophilized extracts on the $\mathrm{O}_{2}^{--}$-induced reduction of NBT at $562 \mathrm{~nm}$.

\subsubsection{Non-enzymatic assay}

Superoxide radicals were generated by the NADH/PMS system according to a described procedure (Valentão et al., 2001a, $2001 \mathrm{~b}$ ). All components were dissolved in phosphate buffer (19 mM, pH 7.4). Three experiments were performed in triplicate.

\subsubsection{Enzymatic assay}

Superoxide radicals were generated by the xanthine/xanthine oxidase $(\mathrm{X} / \mathrm{XO})$ system, following a described procedure (Valentão et al., 2001a, 2001 b). Briefly, xanthine was dissolved in $\mathrm{NaOH}(1 \mu \mathrm{M})$ and subsequently in phosphate buffer $(50 \mathrm{mM})$ with EDTA $(0.1 \mathrm{mM}, \mathrm{pH} 7.8)$, xanthine oxidase in EDTA $(0.1 \mathrm{mM})$ and the remaining components in phosphate buffer $(50 \mathrm{mM})$ with EDTA $(0.1 \mathrm{mM}, \mathrm{pH}$ 7.8). Three experiments were performed in triplicate. 
Table 1

$R_{t}$ and most frequent ions which characterize the MS fragmentation of tronchuda cabbage seeds phenolic compounds

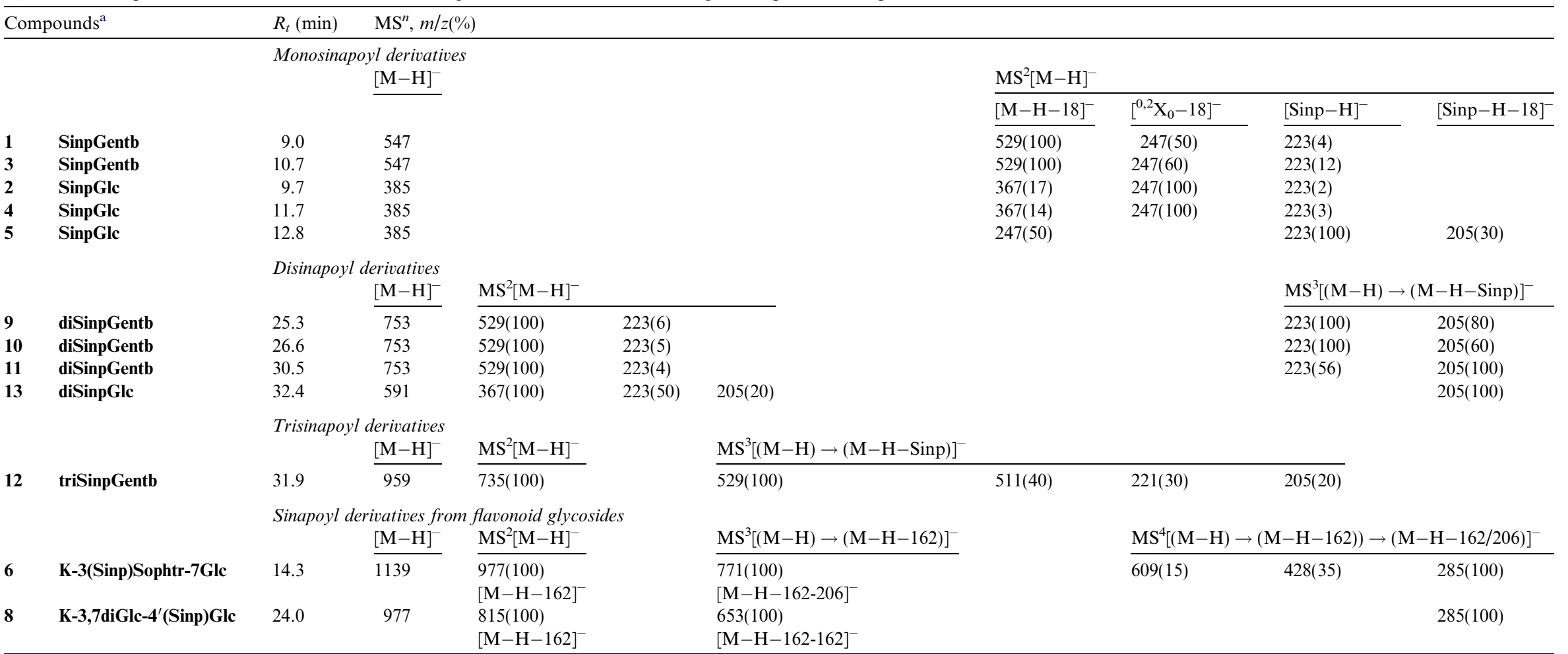

${ }^{\mathrm{a}}$ 1: sinapoylgentiobiose; 2: 1-sinapoylglucose isomer; 3: sinapoylgentiobiose isomer; 4: 1-sinapoylglucose isomer; 5: 1-sinapoylglucose; 6: kaempferol-3-(sinapoyl)sophorotrioside-7-glucoside; 8:

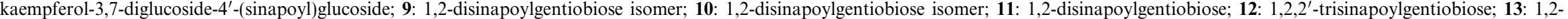
disinapoylglucose. Glc: Glucoside; Gentb: Gentiobioside; Soph: Sophoroside; Sophtr: Sophorotrioside; Sinp: Sinapoyl; K: Kaempferol. 


\subsubsection{Effect on xanthine oxidase activity}

The effect of the lyophilized extracts on xanthine oxidase activity was evaluated by measuring the formation of uric acid from xanthine in a double beam spectrophotometer (He $\lambda$ ios $\alpha$, Unicam), at room temperature, according to a described procedure (Valentão et al., 2001a, 2001 b). The reaction mixtures contained the same proportion of components as in the enzymatic assay for superoxide radicalscavenging activity, except NBT, in a final volume of $750 \mu \mathrm{l}$. The absorbance was measured at $295 \mathrm{~nm}$ for $2 \mathrm{~min}$. Three experiments were performed in triplicate.

\subsection{Hydroxyl radical assay}

The deoxyribose method for determining the scavenging effect of the aqueous extracts on hydroxyl radicals was performed according to a described procedure (Valentão et al., $2001 \mathrm{~b}$ ) in a double beam spectrophotometer (He $\lambda$ ios $\alpha$, Unicam). Reaction mixtures contained $50 \mu \mathrm{M}$ ascorbic acid, $40 \mu \mathrm{M} \mathrm{FeCl}_{3}, 2 \mathrm{mM}$ EDTA, $2.8 \mathrm{mM} \mathrm{H} \mathrm{O}_{2}, 2.8 \mathrm{mM}$ deoxyribose and lyophilized extracts. All components were dissolved in $\mathrm{KH}_{2} \mathrm{PO}_{4}-\mathrm{KOH} 10 \mathrm{Mm}$ buffer, $\mathrm{pH}$ 7.4. This assay was also performed, either without ascorbic acid or EDTA, in order to evaluate the extracts pro-oxidant and metal chelation potential, respectively. Three experiments were performed in triplicate.

\subsection{Hypochlorous acid scavenging activity}

The inhibition of hypochlorous acid-induced 5-thio-2nitrobenzoic acid (TNB) oxidation to 5,5'-dithiobis(2nitrobenzoic acid) was performed according to a described procedure (Valentão et al., 2001 b), in a double beam spectrophotometer (He $\lambda$ ios $\alpha$, Unicam). Hypochlorous acid and TNB were prepared immediately before use. Scavenging of hypochlorous acid was ascertained by using lipoic acid as a reference scavenger, which scavenged $\mathrm{HOCl}$ in a concentration-dependent manner (data not shown). Three experiments were performed in triplicate.

\section{Results and discussion}

\subsection{Characterization of the seed phenolic compounds}

The screening by HPLC-DAD-MS/MS-ESI of the aqueous lyophilized extract of tronchuda cabbage seeds revealed a chromatogram (registered at $330 \mathrm{~nm}$ ) characterized by the existence of several compounds whose UV spectra had a maximum at $\approx 330 \mathrm{~nm}$ (Fig. 1). Some of them (compounds 6 and 8) exhibited a second maximum at $\approx 267 \mathrm{~nm}$, but with lower absorption, indicating the occurrence of flavonoids. These data, together with those obtained in the $\mathrm{MS}^{n}$ IonTrap electrospray ionisation fragmentation study, in which can be observed losses of 224/206 amu (sinapic acid/sinapic acid-18) and ions at $m / z$ 223/205 (deprotonated sinapic acid/deprotonated sinapic acid-18 ions), indicate that these compounds are sinapic acid derivatives. In addition, the HPLC-DAD chromatographic profile was similar to that found before for Brassica napus seeds extracts (Baumert et al., 2005), exhibiting sinapoylcholine, or sinapine (7) (UV $325 \mathrm{~nm}$; +MS: $310[\mathrm{M}]^{+},+\mathrm{MS} 2[\mathrm{M}]^{+}: 251[\mathrm{M}-$ $\left.\left(\mathrm{CH}_{3}\right)_{3} \mathrm{~N}\right]^{+}$as an important compound, extensively described to occur in the Brassica genus (Bell, 1993; Bouchereau et al., 1991; Shahidi \& Naczk, 1992).

Sinapate esters of glucose and gentiobiose (compounds $5,9,10,11,12,13)$ constitute another important group of phenolic compounds already reported in B. napus seeds and other plant organs of $B$. oleracea varieties (Ferreres

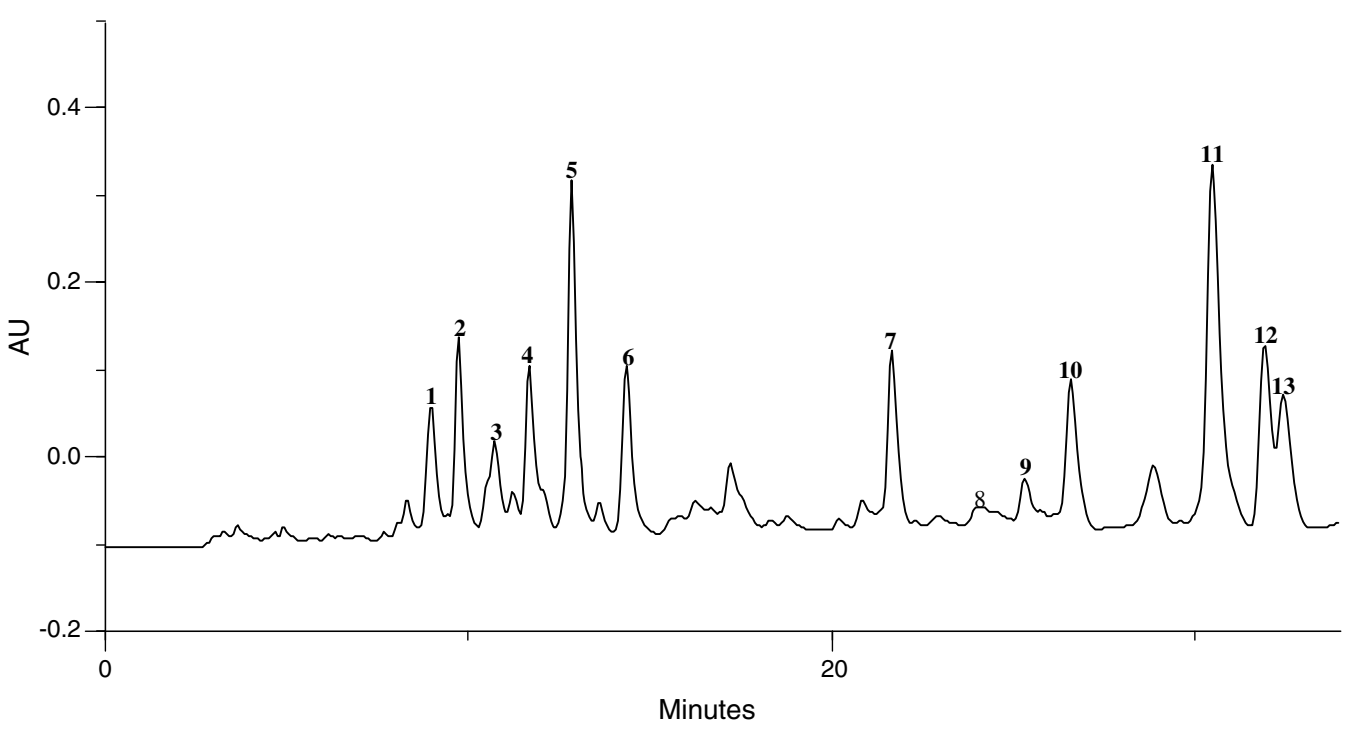

Fig. 1. HPLC-DAD phenolic profile of tronchuda cabbage seeds' aqueous lyophilized extract. Detection at $330 \mathrm{~nm}$. Peaks: (1) sinapoylgentiobiose; (2) 1sinapoylglucose isomer; (3) sinapoylgentiobiose isomer; (4) 1-sinapoylglucose isomer; (5) 1-sinapoylglucose; (6) kaempferol-3-(sinapoyl)sophorotrioside-7glucoside; (7) sinapoylcholine; (8) kaempferol-3,7-diglucoside-4'-(sinapoyl)glucoside; (9) 1,2-disinapoylgentiobiose isomer; (10) 1,2-disinapoylgentiobiose isomer; (11) 1,2-disinapoylgentiobiose; (12) 1,2,2'-trisinapoylgentiobiose; (13) 1,2-disinapoylglucose. 
et al., 2006; Llorach, Gil-Izquierdo, Ferreres, \& TomásBarberán, 2003; Price, Casuscelli, Colquhoun, \& Rhodes, 1997; Vallejo, Tomás-Barberán, \& Ferreres, 2004; Vallejo, Tomás-Barberán, \& Garcia-Viguera, 2003). The -MS ${ }^{n}$ fragmentation observed for these compounds was similar to that described in a previous work (Ferreres et al., 2006), mainly consisting in the loss of sinapic acid (224 amu) or sinapic acid-18 (206 amu), giving rise to the base peak in each $\mathrm{MS}^{n}$ event. In the fragmentation of the last sinapic acid-containing ion, there was base peak at $\mathrm{m} / z$ 223/205 (Table 1). By comparison with data reported before for Brassica seeds (Baumert et al., 2005), we tentatively consider that the compounds detected are 1-sinapoylglucose (5), 1,2-disinapoylgentiobiose (11), 1,2-disinapoylgentiobiose isomers (9 and 10), 1,2,2'-trisinapoylgentiobiose (12) and 1,2-disinapoylglucose (13). Besides these compounds, there were also two 1-sinapoylglucose isomers (compounds 2 and $\mathbf{4}$ ) and two sinapoylgentiobiosides (compounds 1 and 3), with a $\mathrm{MS}^{n}$ fragmentation distinct from that of the sinapate esters described above. In their $-\mathrm{MS}^{2}[\mathrm{M}-\mathrm{H}]^{-}$the ion at $m / z 223$ is not abundant and the loss of the glycosidic fraction is not complete, forming an ion at $\mathrm{m} / \mathrm{z} 247$ $\left[{ }^{0,2} \mathrm{X}_{0}-18\right]^{-}$(Domon \& Costello, 1988) as a result of the partial sugar fragmentation (Table 1). The ion $[\mathrm{M}-\mathrm{H}-18]^{-}$is abundant, being the base peak of the sinapoylgentiobiosides 1 and 3 . The observed fragmentation facility to give rise to a total loss of the glycosyl radical in the case of the sinapate esters, or the partial fragmentation of the sugar in the other compounds, suggests that the sugar-sinapic acid link is of a different nature.

In the sinapoyl derivatives from flavonoid glycosides, the compound at $R_{t} 14.3$ min formed an ion $[\mathrm{M}-\mathrm{H}]^{-}$ whose $\mathrm{MS}^{n}$ fragmentation indicates that its structure is coincident with that of kaempferol-3-(sinapoyl)sophorotrioside-7-glucoside (6) (Llorach et al., 2003; Vallejo et al., 2004). Another flavonoid was also detected (compound 8), presenting a deprotonated molecular ion at $\mathrm{m} / \mathrm{z} 977$, whose $\mathrm{MS}^{n}$ fragmentation consisted of two sequential losses $\left(\mathrm{MS}^{2}\right.$ and $\left.\mathrm{MS}^{3}\right)$ of glucosyl radical $(-162 \mathrm{amu})$ to form the base peak, and of the loss of glucosyl plus sinapoyl radicals $(-162-206)$ to give rise to a deprotonated kaempferol ion as base peak in $\mathrm{MS}^{4}$ (Table 1). This kind of fragmentation indicates the occurrence of glycosylation in three phenolic hydroxyls and, according to other authors (Baumert et al., 2005), should be coincident with kaempferol-3,7-diglucoside-4'-( sinapoyl)glucoside.

All the described compounds are reported for the first time in tronchuda cabbage seeds. With the exception of the 1,2-disinapoylgentiobiose isomers and of 1,2,2'-trisinapoylgentiobiose, described in the internal leaves (Ferreres et al., 2006), none of these compounds have been previously reported in tronchuda cabbage.

\subsection{Seeds phenolic compounds quantitative analysis}

In order to achieve a better characterization of the aqueous lyophilized extract of tronchuda cabbage seeds, its phe- nolic compounds were quantified by HPLC-DAD. The seeds exhibited a high content of phenolic compounds $(\approx 6.0 \mathrm{~g} / \mathrm{kg})$ (Table 2), 1,2-disinapoylgentiobiose (11) being the compound present in highest amounts, representing $\approx 17 \%$ of total phenolics, followed by kaempferol-3-(sinapoyl)sophorotrioside-7-glucoside (6) and 1-sinapoylglucose (5), which corresponded to 15 and $12 \%$ of total compounds, respectively. The 1,2-Disinapoylgentiobiose isomer (9) was the minor compound, accounting for $2 \%$ of total phenolics.

In the phenolic profile of tronchuda cabbage seeds the hydroxycinnamic derivatives are the main phenolics, corresponding to $\approx 80 \%$ of total compounds. This is clearly distinct from what happened with the internal leaves, in which they represented $\approx 46 \%$ of total phenolics (Ferreres et al., 2006), or with the external leaves, in which only flavonol glycosides were determined (Vrchovska et al., 2006).

\subsection{Identification and quantification of organic acids by $H P L C-U V$}

Tronchuda cabbage seeds presented a chemical profile composed by seven identified organic acids: aconitic, citric, ascorbic, malic, quinic, shikimic and fumaric acids (Fig. 2). All these compounds have been previously described in tronchuda cabbage leaves (Ferreres et al., 2006; Vrchovska et al., 2006) and are now reported for the first time in its seeds.

The total organic acid content of tronchuda cabbage seeds $(\approx 16 \mathrm{~g} / \mathrm{kg})$ (Table 3$)$ was similar to that previously found in the leaves (Ferreres et al., 2006; Vrchovska et al., 2006). However, the seeds exhibited a distinct profile, in which ascorbic acid (3) was the main compound, representing $\approx 52 \%$ of total identified organic acids, followed by citric acid $(2)(\approx 28 \%$ of compounds). As observed with tronchuda cabbage leaves (Ferreres et al., 2006; Vrchovska et al., 2006), shikimic (6) and fumaric (7) acids were minor

Table 2

Quantification of tronchuda cabbage seed phenolic compounds ( $\mathrm{mg} / \mathrm{kg}$, dry basis) ${ }^{\mathrm{a}}$

\begin{tabular}{llrr}
\hline & Phenolic compound & Mean & SD \\
\hline $\mathbf{1}$ & Sinapoylgentiobiose & 309 & 0.3 \\
$\mathbf{2}$ & 1-Sinapoylglucose isomer & 368 & 11.7 \\
$\mathbf{3}$ & Sinapoylgentiobiose isomer & 270 & 1.7 \\
$\mathbf{4}$ & 1-Sinapoylglucose isomer & 417 & 9.8 \\
$\mathbf{5}$ & 1-Sinapoylglucose & 703 & 11.5 \\
$\mathbf{6}$ & Kaempferol-3-(sinapoyl)sophorotrioside-7-glucoside & 911 & 17.7 \\
$\mathbf{7}$ & Sinapoylcholine & 376 & 7.1 \\
$\mathbf{8}$ & Kaempferol-3,7-diglucoside-4'-(sinapoyl)glucoside & 267 & 17.6 \\
$\mathbf{9}$ & 1,2-Disinapoylgentiobiose isomer & 152 & 3.2 \\
$\mathbf{1 0}$ & 1,2-Disinapoylgentiobiose isomer & 345 & 2.0 \\
$\mathbf{1 1}$ & 1,2-Disinapoylgentiobiose & 1023 & 37.1 \\
$\mathbf{1 2}$ & 1,2,2'-Trisinapoylgentiobiose & 448 & 2.2 \\
$\mathbf{1 3}$ & 1,2-Disinapoylglucose & 368 & 2.4 \\
& L & 5974 & \\
\hline
\end{tabular}

\footnotetext{
${ }^{a}$ Results are expressed as mean of three determinations. SD standard
} deviation, $\sum$, sum of the determined phenolic compounds. 


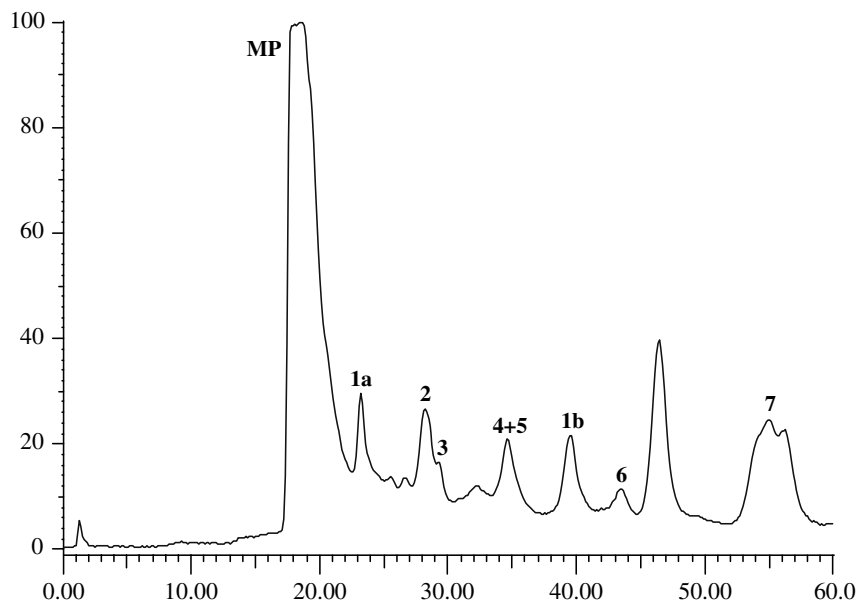

Fig. 2. HPLC-UV organic acid profile of tronchuda cabbage seeds Detection at $214 \mathrm{~nm}$. Peaks: (MP) mobile phase; (1a and $\mathbf{1} \mathbf{~ b})$ aconitic acid isomers; (2) citric acid; (3) ascorbic acid; (4) malic acid; (5) quinic acid; (6) shikimic acid; (7) fumaric acid.

Table 3

Quantification of tronchuda cabbage seeds organic acids $(\mathrm{mg} / \mathrm{kg}$, dry

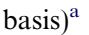

\begin{tabular}{llll}
\hline & Organic acid & Mean & SD \\
\hline $\mathbf{1 a}+\mathbf{1} \mathbf{b}$ & Aconitic & 170 & 2.5 \\
$\mathbf{2}$ & Citric & 4685 & 197 \\
$\mathbf{3}$ & Ascorbic & 8546 & 438 \\
$\mathbf{4}+\mathbf{5}$ & Malic + quinic & 3049 & 222 \\
$\mathbf{6}$ & Shikimic & 18.3 & 0.4 \\
$\mathbf{7}$ & Fumaric & 39.3 & 0.5 \\
& $\sum$ & 16507 & \\
\hline
\end{tabular}

${ }^{\text {a }}$ Results are expressed as means of three determinations; SD, standard deviation; $\sum$, sum of the determined organic acids

compounds, accounting for $\approx 0.1 \%$ and $0.2 \%$ of total acids, respectively.

\subsection{Antioxidant activity}

The $\mathrm{DPPH}^{\cdot}$ assay provides basic information on the antiradical activity of extracts. In this assay, the scavenging of $\mathrm{DPPH}^{*}$ is followed by monitoring the decrease in absorbance at $515 \mathrm{~nm}$, which occurs due to the reduction by the antioxidant (Fukumoto \& Mazza, 2000). In the present study the lyophilized extract of tronchuda cabbage seeds displayed a strong concentration-dependent antioxidant potential $\left(\mathrm{IC}_{25}=64 \mu \mathrm{g} / \mathrm{ml}\right)$ (Fig. 3).

Tronchuda cabbage seeds lyophilized extract scavenged $\mathrm{X} / \mathrm{XO}$-generated superoxide radical in a concentrationdependent way, as shown in Fig. 4, with an $\mathrm{IC}_{25}$ at $197 \mu \mathrm{g} \mathrm{ml}^{-1}$. A control experiment was performed to determine whether the lyophilized extract might inhibit XO, since an inhibitory effect on the enzyme itself would also lead to a decrease in NBT reduction. (Valentão et al., 2001a). However, it was observed that the lyophilized extract had no effect on XO (Fig. 4). The capacity of the lyophilized extract to scavenge superoxide radical in a concentration-dependent manner was confirmed when this

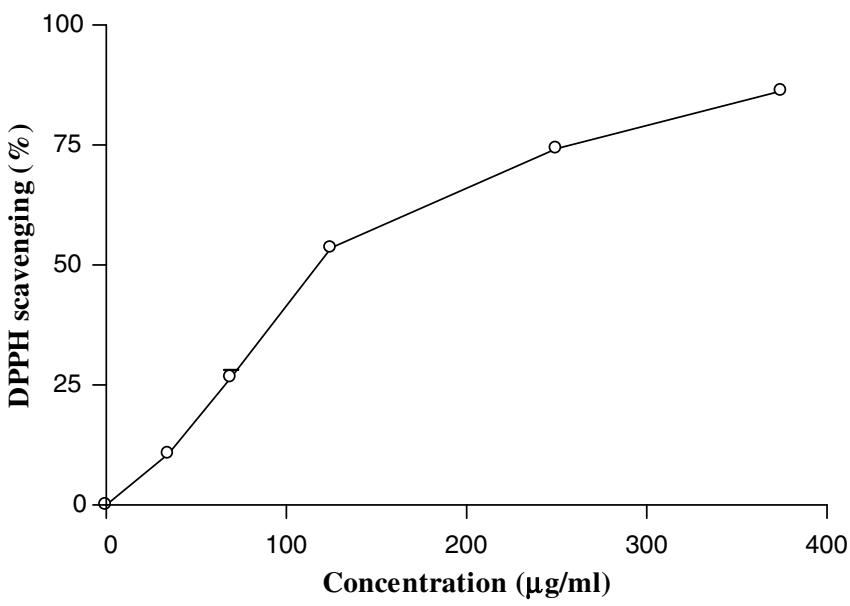

Fig. 3. Effect of tronchuda cabbage seeds on DPPH reduction. Values show mean $\pm \mathrm{SE}$ from three experiments performed in triplicate.

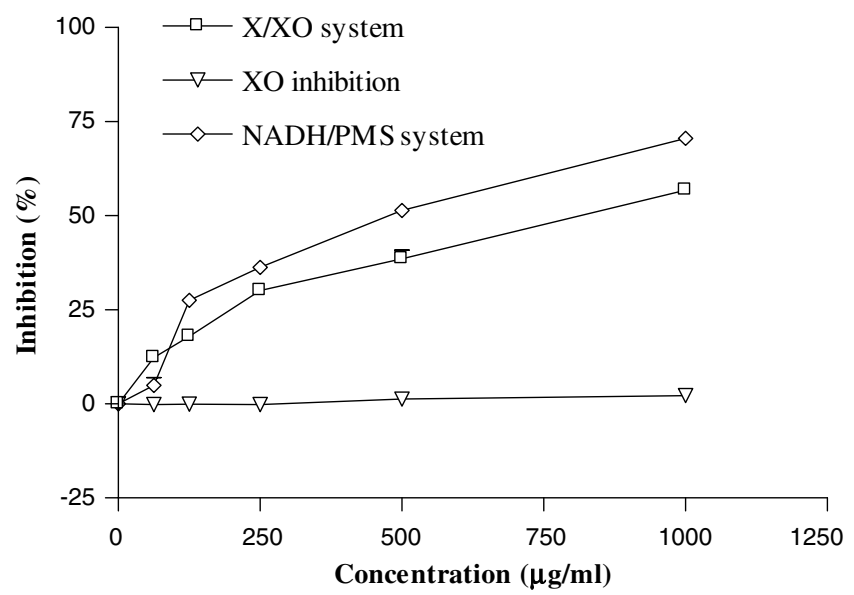

Fig. 4. Effect of tronchuda cabbage seeds against superoxide radical generated in enzymatic (X/XO) and chemical (NADH/PMS) systems and on $\mathrm{XO}$ activity. Values show mean $\pm \mathrm{SE}$ from three experiments performed in triplicate.

radical was generated by a chemical system, which indicated an $\mathrm{IC}_{25}$ at $118 \mu \mathrm{g} \mathrm{ml}^{-1}$ (Fig. 4).

The tronchuda cabbage seeds' lyophilized extract also appeared to be a potent scavenger of hydroxyl radical generated by a Fenton system, in a concentration-dependent manner $\left(\mathrm{IC}_{25}=4 \mu \mathrm{g} \mathrm{ml}^{-1}\right.$ ) (Fig. 5). Some compounds are capable of redox cycling the metal ion required for hydroxyl generation, thus increasing the radical production and, consequently, deoxyribose degradation (Li \& Xie, 2000). So, ascorbic acid was omitted in the assay, in order to check the pro-oxidant capacity of the extract. Under those circumstances, tronchuda cabbage seeds' lyophilized extract proved to be an effective substitute of ascorbic acid for concentrations above $1.9 \mu \mathrm{g} \mathrm{ml}^{-1}$ (Fig. 5). This could be attributed to the high amount of this acid in the seeds. It seems that, at the tested concentrations, tronchuda cabbage seeds have both anti-oxidant and pro-oxidant effects, with the first being more pronounced than the latter. Inhibition of iron-dependent deoxyribose degradation in the 


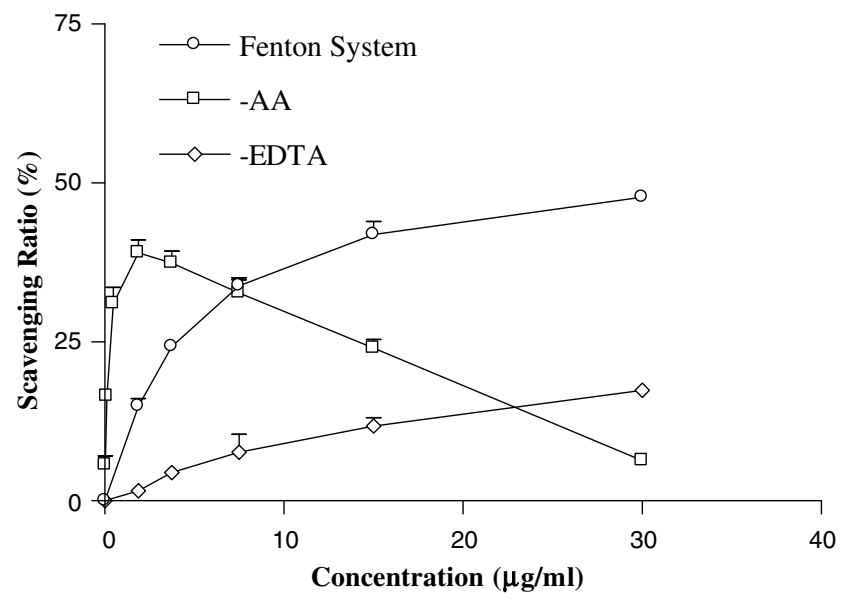

Fig. 5. Tronchuda cabbage seeds' non-specific hydroxyl radical-scavenging activity, pro-oxidant activity (-AA) and specific hydroxyl radicalscavenging (-EDTA). Values show mean \pm SE from three experiments performed in triplicate.

absence of EDTA depends not only on the ability of a scavenger to react with hydroxyl radical, but also on its ability to form complexes with iron ions (Halliwell, Gutteridge, \& Aruoma, 1987). In the assay performed in the absence of EDTA, tronchuda cabbage seeds' lyophilized extract displayed a concentration-dependent ability to chelate iron ions, with an $\mathrm{IC}_{10}$ at $12 \mu \mathrm{g} \mathrm{ml}^{-1}$ (Fig. 5).

Under the present experimental conditions an $\mathrm{HOCl}$ scavenger inhibits the oxidation of $\operatorname{TNB}\left(\lambda_{\max }=412 \mathrm{~nm}\right)$ into DTNB $\left(\lambda_{\max }=325 \mathrm{~nm}\right.$ ) (Künzel, Zee, \& Ijzerman, 1996). Tronchuda cabbage seeds' lyophilized extract exhibited a concentration-dependent protective activity against $\mathrm{HOCl}$ damage $\left(\mathrm{IC}_{10}=87 \mu \mathrm{g} \mathrm{ml}^{-1}\right)$, as shown in Fig. 6 .

According to the results obtained in all assays, and in comparison with data from both tronchuda cabbage internal and external leaves (Ferreres et al., 2006; Vrchovska

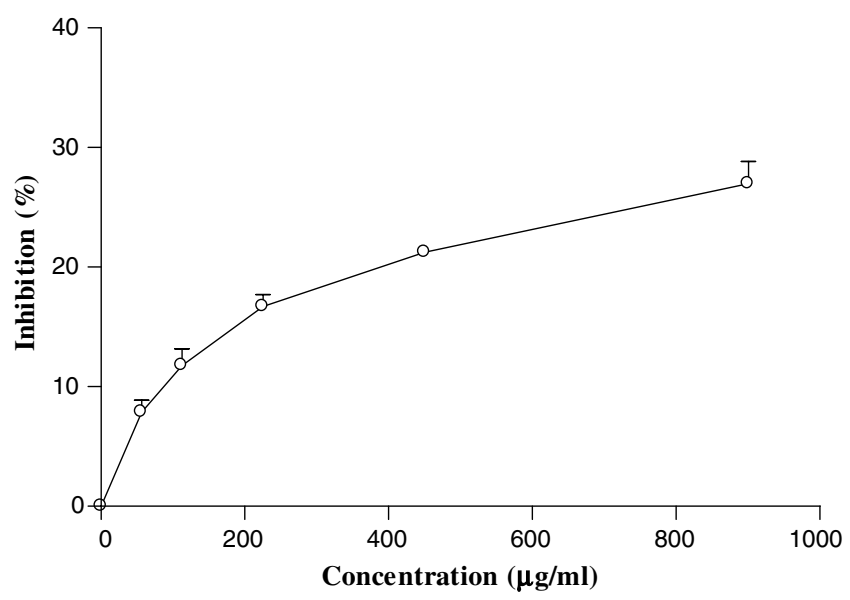

Fig. 6. Effect of tronchuda cabbage seeds on the oxidation of TNB by $\mathrm{HOCl}$. Values show mean $\pm \mathrm{SE}$ from three experiments performed in triplicate. et al., 2006), it could be concluded that, in general terms, tronchuda cabbage seeds exhibit higher antioxidant potential than do its leaves. This is not surprising, since seeds often contain the highest concentration of lipids of any plant tissue, with high levels of polyunsaturated fatty acids. The occurrence of high amounts of phenolic compounds, particularly of hydroxycinnamic derivatives, and organic acids, namely ascorbic acid, in tronchuda cabbage seeds, suggests that these compounds protect storage lipids from oxidation, as observed with tocopherols (Sattler, Gilliland, Magallanes-Lundback, Pollard, \& DellaPenna, 2004), contributing to the viability of seeds and their rapid germination when oxygen demand during germination is high (Andarwulan, Fardiaz, Wattimena, \& Shetty, 1999; Randhir \& Shetty, 2003; Sattler et al., 2004). In fact, either hydroxycinnamic esters (Plumb, Price, Rhodes, \& Williamson, 1997), flavonol glycosides (Braca et al., 2003; Tang, Lou, Wang, Li, \& Zhuang, 2001) or organic acids (Silva et al., 2004) are known to exert antioxidant activity.

In conclusion, the results obtained in this study indicate that tronchuda cabbage seeds may constitute a good source of health-promoting compounds, namely phenolic compounds and organic acids. In addition, the high content of phenolic compounds may be important for the resistance of tronchuda cabbage seeds to downy mildew (Sousa, Dias, \& Monteiro, 1997) and insect pests (Ester et al., 2003), as they are known to exert a protective role against parasite attack (Macheix, Fleuriet, \& Billot, 1990).

\section{Acknowledgement}

The authors are grateful to Fundação para a Ciência e Tecnologia (POCI/AGR/57399/2004) for financial support of this work.

\section{References}

Andarwulan, N., Fardiaz, D., Wattimena, G. A., \& Shetty, K. (1999). Antioxidant activity associated with lipid and phenolic mobilization during seed germination of Pangium edule Reinw. Journal of Agricultural and Food Chemistry, 47, 3158-3163.

Ayaz, F. A., Glew, R. H., Millson, M., Huang, H. S., Chuang, L. T., Sanz, C., et al. (2006). Nutrient contents of kale (Brassica oleracea L. var. acephala DC.). Food Chemistry, 96, 572-579. doi:10.1016/ j.foodchem.2005.03.011.

Baumert, A., Milkowski, C., Schmidt, J., Nimtz, M., Wray, V., \& Strack, D. (2005). Formation of a complex pattern of sinapate esters in Brassica napus seeds, catalyzed by enzymes of a serine carboxypeptidase-like acyltransferase family? Phytochemistry, 66, 1334-1345.

Bell, J. M. (1993). Factors affecting the nutritional value of canola meal: a review. Canadian Journal of Animal Science, 73, 679-697.

Bouchereau, A., Hamelin, J., Lamour, I., Renard, M., \& Larher, F. (1991). Distribution of sinapine and related compounds in seeds of Brassica and allied genera. Phytochemistry, 30, 1873-1881.

Braca, A., Fico, G., Morelli, I., De Simone, F., Tomè, F., \& De Tommasi, N. (2003). Antioxidant and free radical scavenging activity of flavonol glycosides from different Aconitum species. Journal of Ethnopharmacology, 86, 63-67.

Chu, Y. F., Sun, J., Wu, X., \& Liu, R. H. (2002). Antioxidant and antiproliferative activities of common vegetables. Journal of Agricultural and Food Chemistry, 50, 6910-6916. 
Domon, B., \& Costello, C. (1988). A systematic nomenclature for carbohydrate fragmentation in FAB-MS/MS spectra of glycoconjugates. Glycoconjugate Journal, 5, 397-409.

Ester, A., Putter, H., \& Bilsen, J. G. P. M. (2003). de van Filmcoating the seed of cabbage (Brassica oleracea L. convar. Capitata L.) and cauliflower (Brassica oleracea L. convar. Botrytis L.) with imidacloprid and spinosad to control insect pests. Crop Protection, 22, 761-768.

Ferreres, F., Llorach, R., \& Gil-Izquierdo, A. (2004). Characterization of the interglycosidic linkage in di-, tri-, tetra- and pentaglycosylated flavonoids and differentiation of positional isomers by liquid chromatography/electrospray ionization tandem mass spectrometry. Journal of Mass Spectrometry, 39, 312-321.

Ferreres, F., Sousa, C., Vrchovska, V., Valentão, P., Pereira, J. A., Seabra, R. M., et al. (2006). Chemical composition and antioxidant activity of tronchuda cabbage internal leaves. European Food Research \& Technology, 222, 88-98.

Ferreres, F., Valentão, P., Llorach, R., Pinheiro, C., Cardoso, L., Pereira, J. A., et al. (2005). Phenolic compounds in external leaves of tronchuda cabbage (Brassica oleracea L. var. costata DC). Journal of Agricultural and Food Chemistry, 53, 2901-2907.

Finch-Savage, W. E., Côme, D., Lynn, J. R., \& Corbineau, F. (2005). Sensitivity of Brassica oleracea seed germination to hypoxia. Plant Science, 169, 753-759.

Fukumoto, L. R., \& Mazza, G. (2000). Assessing antioxidant and prooxidant activities of phenolic compounds. Journal of Agricultural and Food Chemistry, 48, 3597-3604.

Gitz, III, D. C., Liu, L., \& McClure, J. W. (1998). Phenolic metabolism, growth, and UV-B tolerance in phenylalanine ammonia-lyase-inhibited red cabbage seedlings. Phytochemistry, 49, 377-386.

Halliwell, B., Gutteridge, M. C., \& Aruoma, O. I. (1987). The deoxyribose method: a simple test-tube assay for determination of rate constants for reactions of hydroxyl radicals. Analytical Biochemistry, 165, 215-219.

Hvattum, E., \& Ekeberg, D. (2003). Study of the collision-induced radical cleavage of flavonoid glycosides using negative electrospray ionization tandem quadrupole mass spectrometry. Journal of Mass Spectrometry, $38,43-49$.

Kaoulla, N., MacLeod, A. J., \& Gil, V. (1980). Investigation of Brassica oleracea and Nasturtium officinale seeds for the presence of epithiospecifier protein. Phytochemistry, 19, 1053-1056.

Künzel, J. K. v. F. D, Zee, J. v. D, \& Ijzerman, A. P. (1996). Radical scavenging properties of adenosine and derivatives in vitro. Drug Development Research, 37, 48-54.

Li, C., \& Xie, B. (2000). Evaluation of the antioxidant and pro-oxidant effects of tea catechin oxypolymers. Journal of Agricultural and Food Chemistry, 48, 6362-6366.

Li, J., \& El Rassi, Z. (2002). High performance liquid chromatography of phenolic choline ester fragments derived by chemical and enzymatic fragmentation processes: analysis of sinapine in rape seed. Journal of Agricultural and Food Chemistry, 50, 1368-1373.

Llorach, R., Gil-Izquierdo, A., Ferreres, F., \& Tomás-Barberán, F. A. (2003). HPLC-DAD-MS/MS ESI characterization of unusual highly glycosylated acylated flavonoids from cauliflower (Brassica oleracea $\mathrm{L}$. var. botrytis) agroindustrial byproducts. Journal of Agricultural and Food Chemistry, 51, 3895-3899.

Macheix, J.-J, Fleuriet, A., \& Billot, J. (1990). Fruit phenolics. Boca Raton, Florida: CRC Press, Inc, pp. 246-255.

MacLeod, A. J., MacLeod, G., \& Reader, G. (1989). Evidence for the occurrence of butyl- and isobutylglucosinolates in seeds of Brassica oleacea. Phytochemistry, 28, 1405-1407.

Matsumoto, T., Shimizu, N., Asano, S., \& Itoh, T. (1983). Cooccurrence of c-24 epimeric 24-methyl- $\Delta^{5,22}$-sterols in the seeds of some Brassica and Raphanus species of Cruciferae. Phytochemistry, 22, 1830-1832.

Naczk, M., Amarowicz, R., Sullivan, A., \& Shahidi, F. (1998). Current research developments on polyphenolics of rapeseed/canola: a review. Food Chemistry, 62, 489-502.
Ninfali, P., \& Bacchiocca, M. (2003). Polyphenols and antioxidant capacity of vegetables under fresh and frozen conditions. Journal of Agricultural and Food Chemistry, 51, 2222-2226.

Plumb, G. W., Price, K. R., Rhodes, M. J., \& Williamson, G. (1997). Antioxidant properties of the major polyphenolic compounds in broccoli.. Free Radical Research, 27, 429-435.

Price, K. R., Casuscelli, F., Colquhoun, I. J., \& Rhodes, M. J. C. (1997). Hydroxycinnamic acid esters from broccoli florets. Phytochemistry, 45, 1683-1687.

Randhir, R., \& Shetty, K. (2003). Light-mediated fava bean (Vicia faba) response to phytochemical and protein elicitors and consequences on nutraceutical enhancement and seed vigour. Process Biochemistry, 38, 945-952.

Randhir, R., \& Shetty, K. (2005). Developmental stimulation of total phenolics and related antioxidant activity in light- and dark-germinated corn by natural elicitors. Process Biochem., 40, 1721-1732.

Rangkadilok, N., Nicolas, M. E., Bennet, R. N., Premier, R. R., Eagling, D. R., \& Taylor, P. W. J. (2002a). Determination of sinigrin and glucoraphanin in Brassica species using a simple extraction method combined with ion-pair HPLC analysis. Scientia Horticulturae, 96, $27-41$.

Rangkadilok, N., Nicolas, M. E., Bennet, R. N., Premier, R. R., Eagling, D. R., \& Taylor, P. W. J. (2002b). Developmental changes of sinigrin and glucoraphanin in three Brassica species (Brassica nigra, Brassica juncea and Brassica oleracea var. italica). Scientia Horticulturae, 96, $11-26$.

Sattler, S. E., Gilliland, L. U., Magallanes-Lundback, M., Pollard, M., \& DellaPenna, D. (2004). Vitamin E is essential for seed longevity and for preventing lipid peroxidation during germination. Plant Cell, 16, 1419-1432.

Shahidi, F., \& Naczk, M. (1992). An overview of the phenolics of canola and rapeseed: chemical, sensory and nutritional significance. Journal of the American Oil Chemists Society, 69, 917-924.

Silva, B. M., Andrade, P. B., Valentão, P., Ferreres, F., Seabra, R. M., \& Ferreira, M. A. (2004). Quince (Cydonia oblonga Miller) fruit (pulp, peel and seed) and jam: antioxidant activity. Journal of Agricultural and Food Chemistry, 52, 4705-4712.

Sousa, M. E., Dias, J. S., \& Monteiro, A. A. (1997). Screening Portuguese cole landraces for resistance to sven indigenous downy mildew isolates. Scientia Horticulturae, 68, 49-58.

Tang, Y., Lou, F., Wang, J., Li, Y., \& Zhuang, S. (2001). Coumaroyl flavonol glycosides from the leaves of Ginkgo biloba. Phytochemistry, $58,1251-1256$.

Valentão, P., Andrade, P. B., Rangel, J., Ribeiro, B., Silva, B. M., Baptista, P., et al. (2005). Effect of the conservation procedure on the contents of phenolic compounds and organic acids in chanterelle (Cantharellus cibarius) mushroom. Journal of Agricultural and Food Chemistry, 53, 4925-4931.

Valentão, P., Andrade, P. B., Areias, F., Ferreres, F., \& Seabra, R. M. (1999). Analysis of vervain flavonoids by HPLC/diode-array detector. Its application to quality control. Journal of Agricultural and Food Chemistry, 47, 4579-4582.

Valentão, P., Fernandes, E., Carvalho, F., Andrade, P. B., Seabra, R. M., \& Bastos, M. L. (2001a). Antioxidant activity of Centaurium erythraea infusion evidenced by its superoxide radical scavenging and xanthine oxidase inhibitory activity. Journal of Agricultural and Food Chemistry, 49, 3476-3479.

Valentão, P., Fernandes, E., Carvalho, F., Andrade, P. B., Seabra, R. M., \& Bastos, M. L. (lentão et al., 2001 b). Antioxidative properties of cardoon (Cynara cardunculus L.) infusion against superoxide radical, hydroxyl radical, and hypochlorous acid. Journal of Agricultural and Food Chemistry, 49, 3476-3479.

Vallejo, F., Tomás-Barberán, F. A., \& Ferreres, F. (2004). Characterisation of flavonols in broccoli (Brassica oleracea L. var. italica) by liquid chromatography-UV diode-array detection-electrospray ionisation mass spectrometry. Journal of Chromatography A, 1054, 181-193.

Vallejo, F., Tomás-Barberán, F. A., \& Garcia-Viguera, C. (2003). Effect of climatic and sulphur fertilisation conditions, on phenolic compounds 
and vitamin c, in the inflorescences of eight broccoli cultivars. European Food Research \& Technology, 216, 395-401.

Vaughan, J. G., \& Geissler, C. A. (1997a). The new Oxford book of food plants. New York: Oxford University Press, pp. 166-169.

Vaughan, J. G., \& Geissler, C. A. (ughan and Geissler, 1997 b). The new Oxford book of food plants. New York: Oxford University Press, p. 196.
Vrchovska, V., Sousa, C., Valentão, P., Ferreres, F., Pereira, J. A., Seabra, R. M., \& et al. (2006). Antioxidative properties of tronchuda cabbage (Brassica oleracea L. var. costata DC) external leaves against DPPH, superoxide radical, hydroxyl radical and hypochlorous acid. Food Chemistry, in press (doi:10.1016/ j.foodchem.2005.06.019). 